\title{
Kadı Burhaneddin Divanının İki Yeni Tıpkıbasımı Kadı Burhaneddin Ahmed, Kadı Burhaneddin Divanı Yeni Tupkıbasım. Ankara: Bitlis Eren Üniversitesi Yayınları, 2019; Kadı Burhaneddin Ahmed, Kadı Burhaneddin Divant. Ankara: Türk Dil Kurumu Yayınları, 2020.
}

\author{
Ertuğrul ALEMDAR ${ }^{1}$ (1)
}

Sorumlu yazar/Corresponding author:

Ertuğrul Alemdar (Öğr. Gör.), İstanbul Üniversitesi, Yabancı Diller Yüksekokulu, İstanbul, Türkiye

E-posta: ertugrulalemdar@istanbul.edu.tr ORCID: 0000-0002-4709-3545

Başvuru/Submitted: 29.11.2020 • Revizyon Talebi/Revision Requested: 01.12.2020 • Son Revizyon/Last Revision Received: 03.12 .2020 •

Kabul/Accepted: 04.12 .2020 - Online Yayın/Published Online: 20.12 .2020

Atıf/Citation: Alemdar, Ertugrul. "Kadı Burhaneddin Divanı Yeni Tıpkıbasım," Kadı Burhaneddin Ahmed. Kadı Burhaneddin Divanı, adı eserin tanıtımı. Türkiyat Mecmuası-Journal of Turkology 30, 2 (2020): 811-816. https://doi.org/10.26650/iuturkiyat.836281

Tıpkıbasım yayınları, Türkçenin tarihî metinleri üzerine yapılacak çalışmaların ilk aşamasını ifade eder. Türkçenin tarihî metinlerinin öncelikle çeviri yazısının hazırlanması daha sonra da bu çalışmalar üzerine çeşitli diğer incelemelerin gerçekleşebilmesi için kaliteli tıpkıbasımlara ihtiyaç vardır. Aksi hâlde çalışmalar, tıpkıbasım nüshaları görülmeden yapılacak ve birbirini tekrar eden, dar kapsamda ele alınan konulardan ibaret kalacaktır.

Bu yazıda Kadı Burhaneddin Divanının 2019 ve 2020 yıllarında Bitlis Eren Üniversitesi ve Türk Dil Kurumu tarafından yayımlanan tıpkıbasımları tanıtılacaktır.

Kadı Burhaneddin 14. yüzyılın önemli devlet adamlarından biridir. Hayatının büyük bir kısmı mücadele ve savaşlarla geçmiştir. Türkçeden başka Arapça ve Farsça öğrenmiş, dinî ilimler hakkında öğrenim görmüştür. Bütün bu mücadeleler ve savaşlar içinde 305 varaklık dev bir divanla Türk dili ve edebiyatına da hizmet etmiştir. Yaşar Yücel'e göre Kadı Burhaneddin "âlim, âdil, vakar sahibi, keskin zekâlı, yorgunluğa, sıcağa, susuzluğa dayanıklı, sırasında sert konuşur, kimseden çekinmez fakat aynı zamanda zevk ve safaya düşkün, şarap ve saz toplantılarından çok hoşlanan, iyi kalpli, hoşmeşrep ve bilginlere yakın, hassas 
bir adam"dır." Ali Alparslan, "Onu, devrinin orijinal bir sanatçısı yapan tarafı, sevgilinin güzellik unsurlarını dile getirmesi ve edebiyatımıza yeni teşbih ve mecazlar katması ve Türk nazmını kendine has bir anlayışla işlemesidir."2 diyerek Kadı Burhaneddin'in şâirliği ile ilgili görüşlerini ifade etmiştir.

Kadı Burhaneddin Divanının tıpkıbasımı ilk kez 1943 yılında Türk Dil Kurumu tarafından yayımlanmıştır. Dönemin görüntüleme ve basma teknolojileri maalesef iyi bir yayına müsaade etmemiştir. Daha 1980 yılında Muharrem Ergin eserin yeni bir tıpkıbasıma ihtiyacı olduğunu şu sözlerle ifade etmiştir: “... Fakat bu faksimile o günkü baskı şartlarında başarılı olmamış, sayfaların büyük bir kısmı siyah çıkmıştır. Bizim metnimiz de maalesef önce bu faksimileden hazırlanarak matbaaya verildi. Ancak baskıdan önce eserin filmini getirterek temiz fotokopilerini yaptırdık ve metni bu fotokopilere göre yeniden elden geçirerek tashih ettik. Asıl eserin ve elimizdeki fotokopilerin yalnız iki sayfasında yazıyı kapatan siyah lekeler mevcuttur. Buradaki okunmaz mısralara metnimizde noktalarla işaret edilmiştir. Bunun dışında bütün fotokopi sayfaları pırıl pırıldır. Bu haliyle eserin yeni bir faksimilesinin yapılması çok temenniye değer."’

Muharrem Ergin'in 1980 yılındaki temennisi 39 yıl sonra 2019 yılında karşılık bulmuş, Dr. Öğr. Üyesi Hatice Özdil'in hazırladığı proje, Bitlis Eren Üniversitesi Bilimsel Araştırma Projeleri / Kültür - Sanat Projesi kapsamında desteklenmiş ve Kadı Burhaneddin Divanı Yeni Tıpkıbasım adlı eser Bitlis Eren Üniversitesi Yayınları arasında yer almıştır.

Titizlikle hazırlanan bu çalışmanın cildi turkuaz renklidir. Eserin cildinde divanın adı, Dr. Öğr. Üyesi Özgür Çetintaş tarafından tasarlanmış olan Arap harfli hat yazıyla yer almaktadır. Yazmanın sayfaları tıpkıbasıma tam boy olarak basılmış, yazmanın varak görüntülerinin dışında tıpkıbasımın sayfa kenarlarında beyazlıklar görünmemektedir. Bu sayede tıpkıbasım bir nebze gerçek bir yazma hissi uyandırmaktadır. Sayfalarda satır numaraları 1, 5, 10, 15 şeklinde yer almış; bu da tıpkıbasımın kullanımını kolaylaştıran bir unsur olmuştur. Eserin sayfa genişlikleri 29 × $21 \mathrm{~cm}$ ölçülerindedir. Eser, renkli basılmış ve gayet okunaklıdır. Tüm bu niteliklere rağmen eserin temini çok güçtür. Eser sadece Bitlis Eren Üniversitesi Kütüphanesinden "dilekçe ile talep edilerek" temin edilebilmektedir. Eserin dağıtımında seçeneklerin artırılması araştırmacıların esere ulaşımını kolaylaştıracaktır.

Türk Dil Kurumu 2020 yılının Ağustos ayında Kadı Burhaneddin - Divan adlı eseri tıpkıbasım olarak yayımlamıştır. Eserin cildi laciverttir. Eserin adı Latin kökenli Türk harfleriyle ve Türk Dil Kurumunun logosu altın sarısı renkte ciltte yer almaktadır. Yayının ön sözü Türk Dil Kurumu Başkanı, Prof. Dr. Gürer Gülsevin tarafından, eserin içeriğinden bahsedildiği giriş kısmı da Marmara Üniversitesi Eğitim Fakültesi Öğretim Üyesi Prof. Dr. Mustafa S. Kaçalin tarafından yazılmıştır. Bu neşirde, yazmanın sayfaları tıpkıbasımda

Yaşar Yücel, Kadı Burhaneddin (Ankara: Kültür ve Turizm Bakanlığı Yayınları, 1987), 44.

Ali Alparslan, Kadı Burhaneddin Divanından Seçmeler (Ankara: Kültür Bakanlığı Yayınları, 1977), XLIII.

Muharrem Ergin, Kadı Burhaneddin Divanı (İstanbul: İstanbul Üniversitesi Edebiyat Fakültesi Yayınları, 1980), V. 
küçük kalmış, tıpkıbasımdaki sayfalarının kenarlarındaki beyazlıklar eserin gerçekçiliğini azaltmıştır. Tıpkıbasımın sayfalarında satır numaralarına yer verilmemiştir. Tıpkıbasımın sayfa genişlikleri 24 x $16 \mathrm{~cm}$ ölçülerindedir. Eser, renkli basılmış ve gayet okunaklıdır. Eserde bir varak eksiktir. Bunun nedeni 171r. ve 171v. sayfalarının 172r. ve 172v. sayfaları yerine aynen kopyalanmış olmasıdır. Buradan öncesi ve sonrası tamdır ve eksik başka sayfa bulunmamaktadır.

TDK yayınında eksik olan sayfalar Bitlis Eren Üniversitesi yayınından alınarak aşağıda verilmişstir.

TDK'ye göre 172r. / BEÜ'ye göre 171b

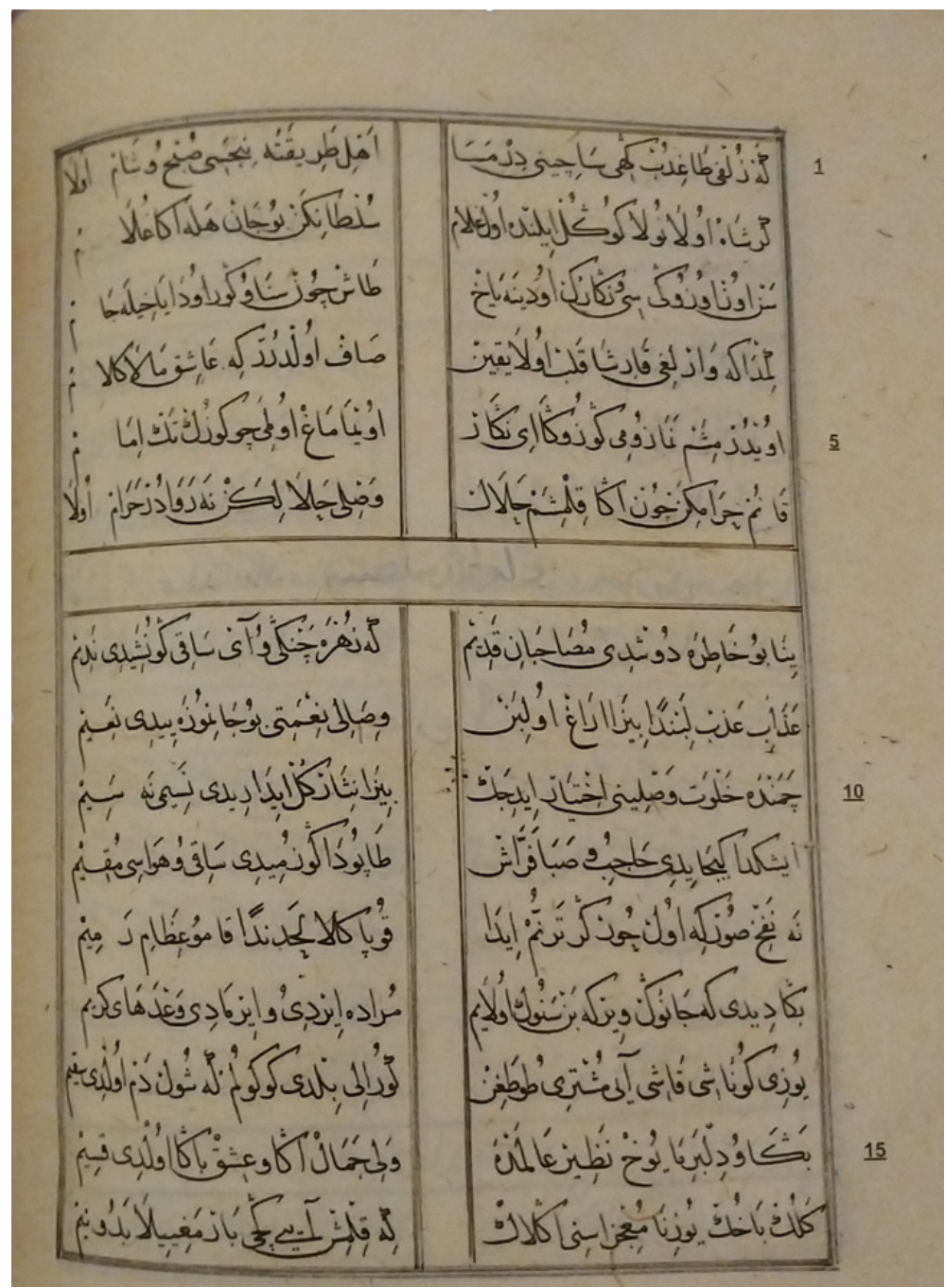


TDK'ye göre 172v. / BEÜ'ye göre 172a

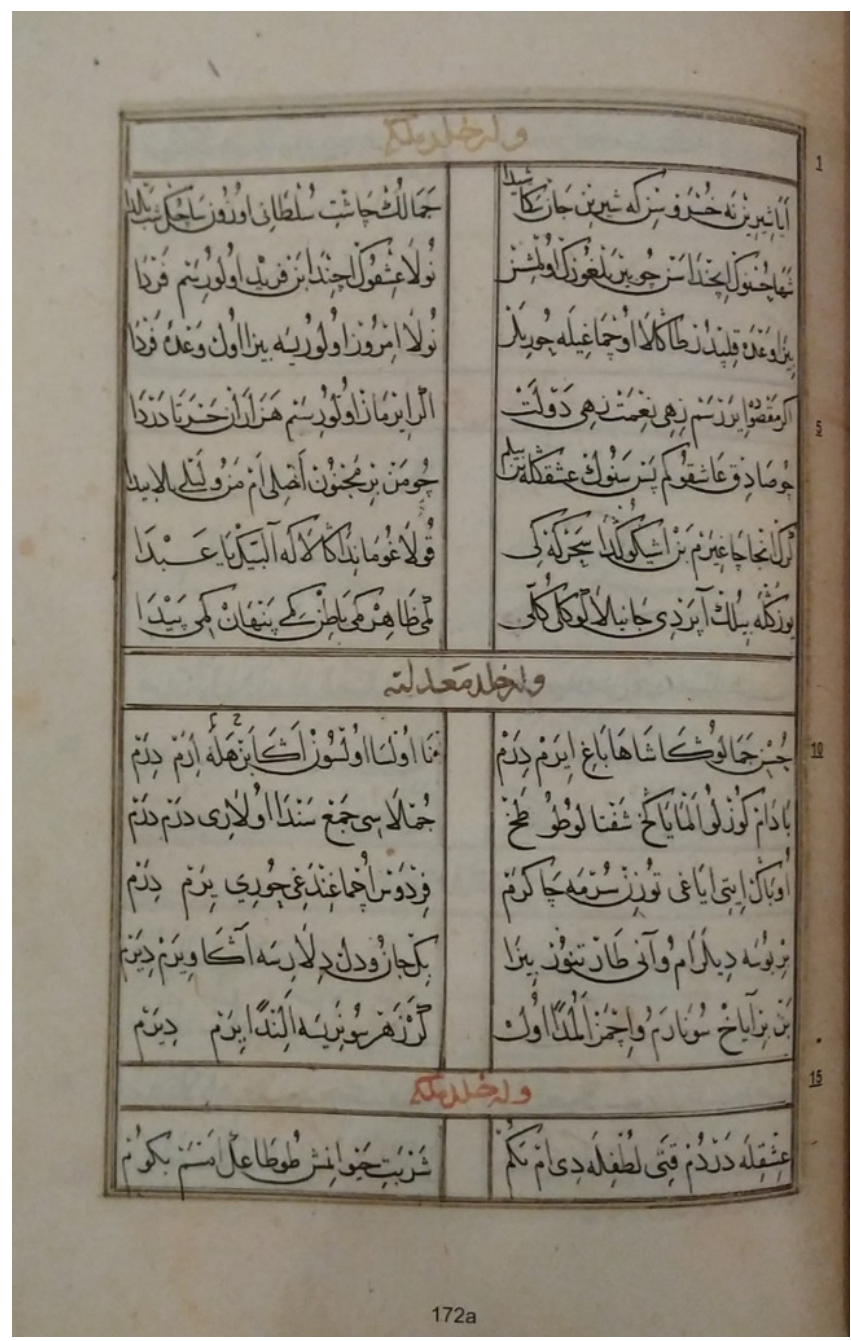

Her iki yayın da Türklük bilimi sahasında uzun süredir hissedilen bir eksikliği ortadan kaldırmıştır. $\mathrm{Bu}$ tarz çalışmaların ve onlara verilen desteklerin artarak devam etmesini temenni ederiz.

\section{Kaynaklar/References}

Alparslan, Ali. Kadı Burhaneddin Divanından Seçmeler. Ankara: Kültür Bakanlığı Yayınları, 1977.

Ergin, Muharrem. Kadı Burhaneddin Divanı. İstanbul: İstanbul Üniversitesi Edebiyat Fakültesi Yayınları, 1980. Yücel, Yaşar. Kadı Burhaneddin. Ankara: Kültür ve Turizm Bakanlığı Yayınları, 1987. 
EK 1. Dış Kapak (Kadı Burhaneddin Ahmed, Kadı Burhaneddin Divanı Yeni Tıpkıbasım. Ankara: Bitlis Eren Üniversitesi Yayınları, 2019)

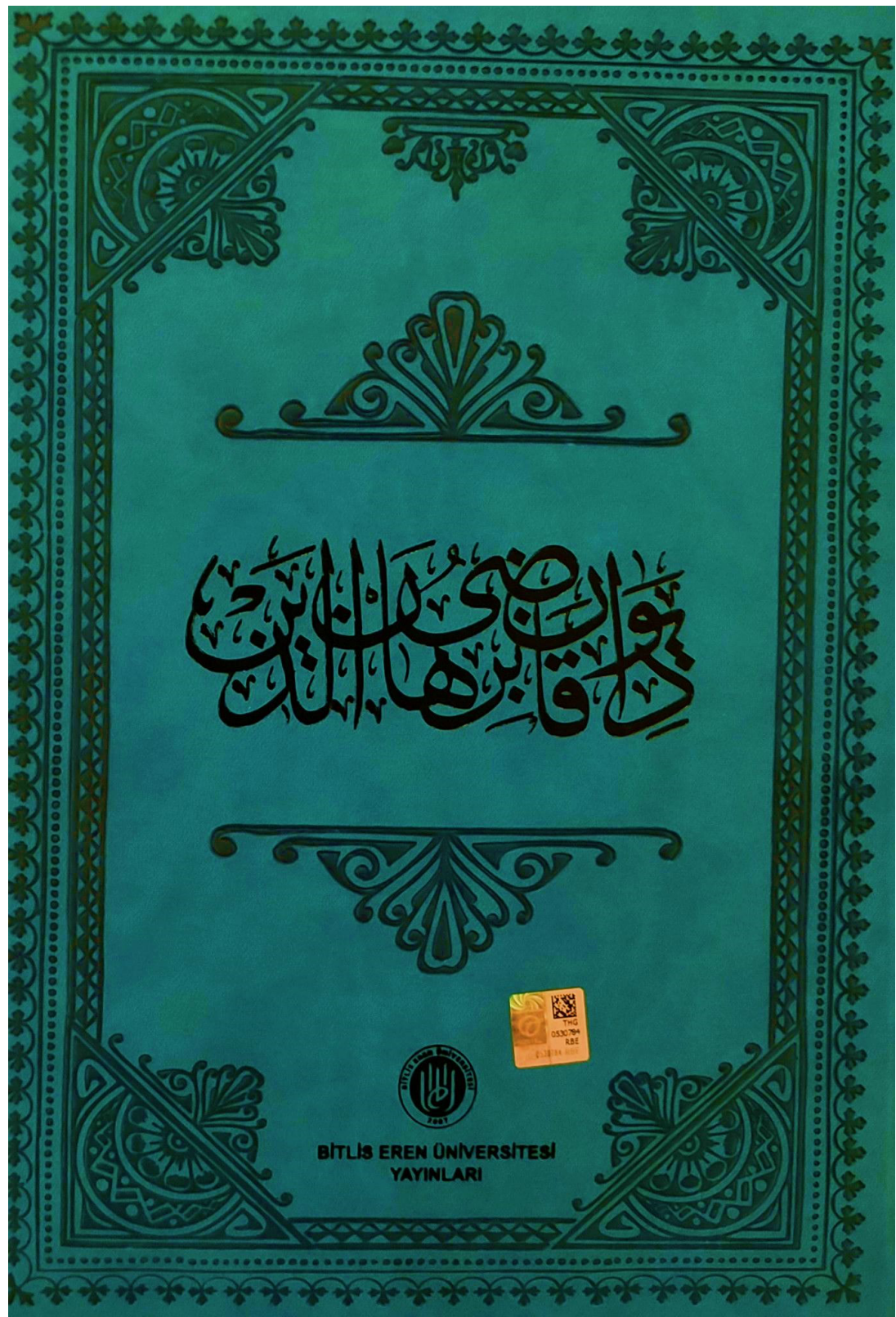


EK 2. Dış Kapak (Kadı Burhaneddin Ahmed, Kadı Burhaneddin Divanı. Ankara: Türk Dil Kurumu Yayınları, 2020)

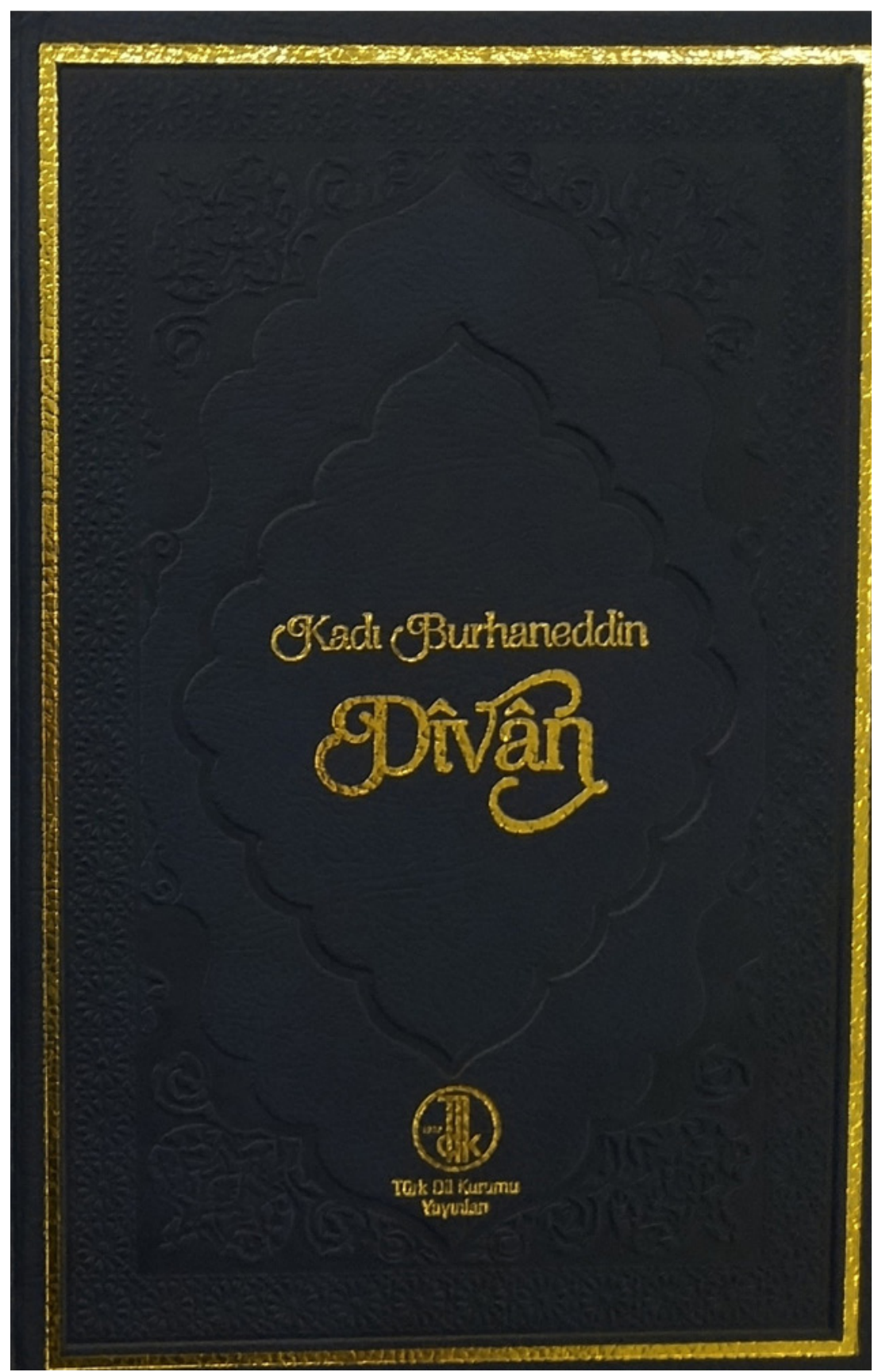

